\title{
Daily rhythmicity of clock gene transcript levels in fast and slow muscle fibers from Chinese perch (Siniperca chuatsi)
}

\author{
Ping $\mathrm{Wu}^{1 \dagger}$, Yu-Long $\mathrm{Li}^{1 \dagger}$, Jia Cheng ${ }^{1 \dagger}$, Lin Chen ${ }^{1}$, Xin Zhu' ${ }^{1}$, Zhi-Guo Feng ${ }^{3}$, Jian-She Zhang ${ }^{1,2^{*}}$ and Wu-Ying Chu ${ }^{1,2^{*}}$
}

\begin{abstract}
Background: Clock genes are considered to be the molecular core of biological clock in vertebrates and they are directly involved in the regulation of daily rhythms in vertebrate tissues such as skeletal muscles. Fish myotomes are composed of anatomically segregated fast and slow muscle fibers that possess different metabolic and contractile properties. To date, there is no report on the characterization of the circadian clock system components of slow muscles in fish.
\end{abstract}

Results: In the present study, the molecular clock components (clock, arnt/1/2, cry1/2/3, cry-dash, npas2, nr1d1/2, per1/2/3, rora and tim genes) and their daily transcription levels were characterized in slow and fast muscles of Chinese perch (Siniperca chuatsi). Among the 15 clock genes, nrld2 and per3 had no daily rhythmicity in slow muscles, and cry $2 / 3$ and tim displayed no daily rhythmicity in fast muscles of the adult fish. In the slow muscles, the highest expression of the most clock paralogs occurred at the dark period except arnt11, nr1d1, nrld2 and tim. With the exception of $n r 1 d 2$ and tim, the other clock genes had an acrophase at the light period in fast muscles. The circadian expression of the myogenic regulatory factors ( $m r f 4$ and myf5), mstn and pnca showed either a positive or a negative correlation with the transcription pattern of the clock genes in both types of muscles.

Conclusions: It was the first report to unravel the molecular clock components of the slow and fast muscles in vertebrates. The expressional pattern differences of the clock genes between the two types of muscle fibers suggest that the clock system may play key roles on muscle type-specific tissue maintenance and function.

Keywords: Chinese perch, Clock genes, Skeletal muscle, Daily rhythmicity, Myogenic regulatory factors

\section{Background}

Fish skeletal muscles are the most abundant tissue in the body mass and play an important role in the process of certain physiological metabolism [1]. Similar to other peripheral tissues of the body, skeletal muscles have circadian rhythms [2]. These rhythms are regulated by a transcriptional-translational and post-translational feedback network termed as the molecular clock [3]. There are several major components in the molecular clock, including circadian locomotor output cycles kaput (clock), aryl hydrocarbon receptor nuclear translocatorlike protein 1 (arntl1 or bmal1), cryptochrome (cry), and

\footnotetext{
* Correspondence: jzhang@ccsu.edu.cn; chuwuying18@163.com ${ }^{\dagger}$ Equal contributors

${ }^{1}$ Department of Bioengineering and Environmental Science, Changsha University, Changsha, Hunan 410003, China

Full list of author information is available at the end of the article
}

period protein (per) etc. [4]. Two transcriptional activation proteins of the molecular clock, namely clock and arntl1, are the basic-helix-loop-helix (bHLH) transcription factors that form into a heterodimer in the nucleus. Together, they transactivate per and cry gene expression via binding to the E-box elements (CACGTG) at their promoter sequences [5-7]. Per and cry then translocate into the cell nucleus, in which they inactivate clock and arntl activity, thereby repressing their own transcription. The clock mechanism plays a pivotal role in myogenesis, gene transcription, and maintenance of muscle metabolism $[8,9]$. The molecular clock components have been identified in skeletal muscles and showed a circadian rhythms of expression. In addition to these clock genes, more than 2300 other genes have circadian pattern of expression in skeletal muscles. These muscle genes with circadian pattern of expression are believed to be 
regulated by the major molecular clock genes and the clock-controlled transcription factors [10].

Fish are excellent model species for investigating the regulation of skeletal muscle physiology in vertebrates because it has several structural features making convenient to experimental analysis $[11,12]$. The slow-contracting red and fast-contracting white muscles are the two main muscle fiber types in fish [13, 14]. Particularly, they are localized into physically distinct area of the fish body. The fast muscle fibers are the main component of skeletal muscles that distribute along the spine of the whole body. Their explosive force is strong for fast swimming using energy from glycolysis $[15,16]$. Slow fibers, on the other hand, contain high contents of mitochondria and their metabolism is completely aerobic [16, 17]. These unique features enable slow fibers to maintain sustained swimming and support oxygen respiration [18].

Recently, several studies have been reported on the clock rhythmicity in fish. In zebrafish, the major clock genes showed similar circadian expression patterns in fast muscles compared with the central organs, such as retina and brain $[19,20]$. It has been shown that insulinlike growth factor binding proteins (igfbp 3 and $i g f b p 5 b)$ and myogenic regulatory factor $4(m r f 4)$ were controlled by the core clock genes in zebrafish skeletal muscles [20, 21]. In Atlantic cod fast muscles, similar circadian clock system has been identified [2]. Another myogenic regulatory factor myf5 exhibited a significant correlation with the core clock genes at the transcription levels [2]. However there is little information on the circadian clock system components in fish slow muscle. The Chinese perch (Siniperca chuatsi) is one of the most important species in aquaculture in China [22]. Its high nutritional value, high protein content and appealing taste have led to its expanded large-scale aquaculture in china [23]. In the present study, we report the characterization of circadian clock system in both fast and slow muscles of Chinese perch, and the correlation analysis between core clock gene expression and 11 myogenic related genes in the two types of muscles.

\section{Results}

Isolation of Chinese perch clock genes and their molecular characteristics

A total of 4 complete and 11 partial sequences of 15 clock genes were cloned from the skeletal muscles of Chinese perch. These include arntl1, arntl2, clock, cry1, cry2, cry3, cry-dash, npas2, nr1d1, nr1d2, per1, per2, per3, rora and tim (Additional file 1). The full-length cDNAs of clock, cry1, per1 and nr1d2 were 3698 bp, 3476 bp, 5406 bp and $2684 \mathrm{bp}$, respectively (Fig. 1). The clock gene contained the $5^{\prime}$-non-coding region ( $5^{\prime}$-UTR) of $412 \mathrm{bp}$, an open reading frame (ORF) of $2697 \mathrm{bp}$ and the 3 '-non-coding region (3'-UTR) of $589 \mathrm{bp}$. The cry1 gene contained the

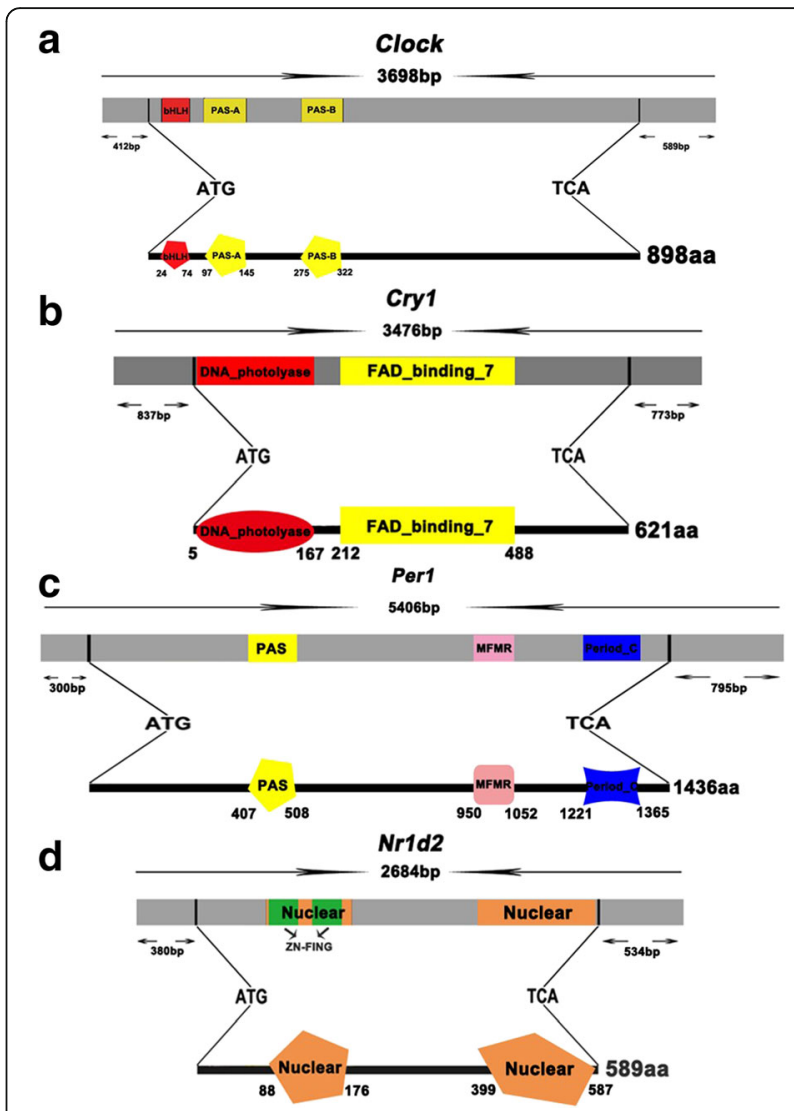

Fig. 1 Schematic representation of the Chinese perch clock gene structure: (a) Clock; (b) Cry; (c) Per1; (d) Nrld2. The predicted domain structure of clock, cry 1 , per1 and $n r 1 d 2$ are shown as above and presented below the sequence structure. The split domain of clock proteins is shown in different colors. Both clock and per1 proteins have a PAS domain. cry 1 includes a photosensitive domain of DNA photolyase, and $n r 1 d 2$ has a unique zinc finger structure that connects with the nuclear DNA

5 '-UTR of $837 \mathrm{bp}$, an ORF of $1866 \mathrm{bp}$ and the 3 '-UTR of $773 \mathrm{bp}$. The per 1 gene included the $5^{\prime}$-UTR of $300 \mathrm{bp}$, an ORF of $4311 \mathrm{bp}$ and the $3^{\prime}$-UTR of $795 \mathrm{bp}$. The $n$ rld 2 gene contained the $5^{\prime}$-UTR of $380 \mathrm{bp}$, an ORF of $1770 \mathrm{bp}$ and the $3^{\prime}$-UTR of $534 \mathrm{bp}$.

The conserved structural and functional domains were characterized based on the predicted protein sequences. The clock protein contains the conserved bHLH, Per-Arnt-Ser (PAS) A and PAS B domains. The amino acid sequences of these domains showed $100 \%, 98 \%$ and $100 \%$ similarities to those of Larimichthys crocea, respectively (Figs. 1 and 2). The per 1 has a PAS domain, a G-box binding protein multifunctional mosaic region (MFMR) and a 2/3 C-terminal region of period protein. The amino acid sequences of these domains showed 99\%, 91\% and 93\% similarities to those of L. crocea, respectively. The cry1 contains two functional domains, a flavin adenine dinucleotide (FAD)-binding domain and a DNA photolyase domain. The amino acid sequences of 


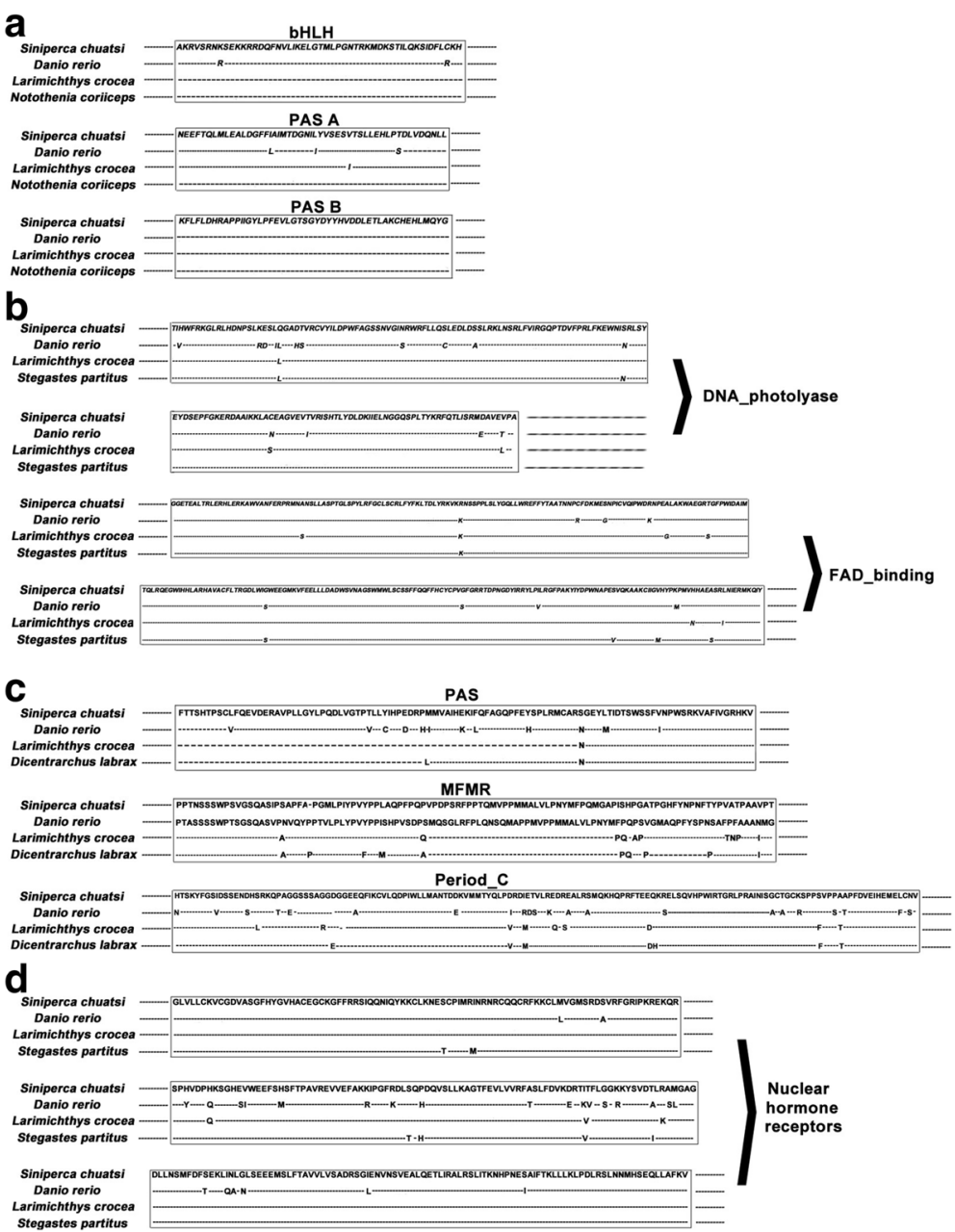

Fig. 2 Amino acid Sequences alignment of functional domains of Chinese Perch 4 clock proteins with the homologous clock proteins of other species: (a) Clock; (b) Cry1; (c) Per1; (d) Nr1d2. The box indicates the functional regions of clock proteins

these two domains showed $98 \%$ and $98 \%$ similarities to those of $L$. crocea, respectively. The $n r 1 d 2$ has two nuclear hormone receptors DNA-binding domains and the amino acid sequences of these domains showed $100 \%$ and $98 \%$ similarities to those of $L$. crocea, respectively.

\section{The rhythmicity of clock genes during a daily cycle in fast and slow muscles}

The expression pattern of the clock genes was determined for daily rhythmicity in fast and slow muscle (Tables 1 and 2, and Figs. 3 and 4). Among the 15 clock genes, $n r 1 d 2$ and per3 have no daily rhythmicity in slow muscles, while cry3, npas2, and tim have no rhythmicity in fast muscle. Cry 2 and cry-dash have no daily rhythmicity in neither slow nor fast muscles. In contrast, arntl1, arntl2, clock, cry1, per1, per2, nr1d1 and rora displayed the daily rhythmicity in both fast and slow skeletal muscles. In fast muscles, transcriptional activation factors arntl1, arntl2 and clock displayed the daily rhythmicity with an acrophase during the light phase (Fig. 3). There was no much temporal difference between arntl2 and clock expression. In slow skeletal muscles, arntl1, arntl2 and clock still displayed the daily rhythmicity but arntl1 had an acrophase during the dark phase (Fig. 4). The temporal expression of arntl1 and clock showed no apparent difference. Finally, npas2 showed the daily rhythmicity with an acrophase during the light phase only in slow muscles (Fig. 4).

The transcriptional repressors $c r y 2, c r y 3$ and tim were arrhythmic but cry1, per1, per2 and per3 were rhythmic in fast muscles. With the exception of tim, the other clock genes were expressed with the acrophase during the light phase in fast muscles. In slow muscles, the cry 2 and per 3 were arrhythmic but cry 1, cry3, per 1 , per 2 and tim were rhythmic. The tim was highly expressed during the light phase with the acrophase at Zeitgeber time $(\mathrm{ZT})=0.16 \mathrm{~h}$, but the other genes were expressed with the acrophase during the dark phase in slow muscles. 
Table 1 Rhythmicity parameters of clock genes and muscle-related genes transcription in Chinese perch fast skeletal muscle

\begin{tabular}{|c|c|c|c|c|}
\hline Gene name & Amplitude & $P$ value & Mesor & Acrophase \\
\hline arntl1 & 0.36 & 0.21 & 0.54 & 2.75 \\
\hline arntl2 & 0.53 & 0.07 & 0.62 & 1.77 \\
\hline cry1 & 0.44 & 0.17 & 0.52 & 1.66 \\
\hline cry2 & 0.12 & 0.46 & 0.27 & 2.89 \\
\hline cry3 & 0.15 & 0.49 & 0.48 & 2.39 \\
\hline npas2 & 0.11 & 0.45 & 0.30 & 2.16 \\
\hline nr1d1 & 0.33 & 0.17 & 0.28 & 1.32 \\
\hline $\mathrm{nr} 1 \mathrm{~d} 2$ & 0.20 & 0.10 & 0.46 & 5.37 \\
\hline per1 & 0.31 & 0.13 & 0.66 & 2.11 \\
\hline per2 & 0.39 & 0.06 & 0.34 & 1.26 \\
\hline per3 & 0.25 & 0.16 & 0.27 & 1.36 \\
\hline rora & 0.16 & 0.20 & 0.28 & 2.86 \\
\hline tim & 0.02 & 0.98 & 0.40 & 4.27 \\
\hline clock & 0.25 & 0.10 & 0.23 & 1.41 \\
\hline crydash & 0.12 & 0.49 & 0.61 & 2.13 \\
\hline foxk2 & 0.07 & 0.89 & 0.31 & 3.82 \\
\hline mbnl1 & 1.30 & 0.07 & 1.02 & 1.63 \\
\hline mrf4 & 0.26 & 0.04 & 0.55 & 2.82 \\
\hline mstn & 0.22 & 0.21 & 0.27 & 0.88 \\
\hline murf1 & 0.04 & 0.91 & 0.30 & 3.52 \\
\hline myf5 & 0.20 & 0.26 & 0.30 & 0.70 \\
\hline myoD & 0.37 & 0.04 & 0.51 & 1.21 \\
\hline myoG & 0.30 & 0.01 & 0.29 & 1.47 \\
\hline pdk4 & 0.17 & 0.48 & 0.39 & 1.09 \\
\hline pena & 0.29 & 0.05 & 0.32 & 6.00 \\
\hline ucp3 & 0.05 & 0.91 & 0.28 & 3.38 \\
\hline
\end{tabular}

Note: Expression levels of clock genes and muscle-related genes are highlighted in bold while they displayed daily rhythmicity. The $P$ value is defined as the noise/signal ratio of the oscillation amplitude. Daily rhythmicity is indicated when $P$ value is less than 0.3

The nuclear receptors ror $\alpha$, $n r 1 d 1$ and $n r 1 d 2$ displayed the daily rhythmicity in fast muscles. rora and $n r 1 d 1$ had an acrophase during the light phase $(\mathrm{ZT}=5.05 \mathrm{~h})$ but $n r 1 d 2$ had an acrophase during the dark phase $(\mathrm{ZT}=$ $20.51 \mathrm{~h}$ ). In slow muscles, rora and $n r 1 d 1$ exhibited a daily rhythmic expression but nrld2 was arrhythmic. The rora and nr1d1 genes had an acrophase during the light phase, but $n r 1 d 2$ exhibited a similar process during the dark phase $(\mathrm{ZT}=19.08 \mathrm{~h})$.

In fast muscles, the mRNA transcript levels of clock were positively correlated with the expression pattern of per 2 and per3 in fast muscles with a higher correlation index $(r>0.8$; Table 3). Arntl2 also exhibited a positive correlation with per 2 and per 3 . Nrld2, however, showed a moderate negative correlation to arntl1, clock, npas2, nr1d1and rora. In slow muscles,clock showed a moderate
Table 2 Rhythmicity parameters of clock genes and muscle-related genes transcription in Chinese perch slow skeletal muscle

\begin{tabular}{|c|c|c|c|c|c|}
\hline Gene name & Amplitude & $P$ value & Mesor & Acrophase & $\mathrm{ZT}(\mathrm{h})$ \\
\hline arntl1 & 0.16 & 0.18 & 0.24 & 0.06 & 0.22 \\
\hline arntl2 & 0.18 & 0.29 & 0.33 & 5.49 & 20.96 \\
\hline cry1 & 0.49 & 0.01 & 0.42 & 5.53 & 21.12 \\
\hline cry2 & 0.13 & 0.64 & 0.42 & 6.19 & 23.65 \\
\hline cry3 & 0.18 & 0.084 & 0.27 & 5.41 & 20.66 \\
\hline npas2 & 0.24 & 0.25 & 0.34 & 0.71 & 2.69 \\
\hline nr1d1 & 0.21 & 0.04 & 0.48 & 1.19 & 4.56 \\
\hline $\mathrm{nr} 1 \mathrm{~d} 2$ & 0.19 & 0.37 & 0.40 & 4.99 & 19.08 \\
\hline per1 & 0.20 & 0.03 & 0.40 & 5.37 & 20.53 \\
\hline per2 & 0.38 & 0.05 & 0.48 & 5.39 & 20.60 \\
\hline per3 & 0.19 & 0.38 & 0.40 & 5.10 & 19.50 \\
\hline rora & 0.25 & 0.04 & 0.42 & 5.69 & 21.75 \\
\hline tim & 0.21 & 0.21 & 0.60 & 0.04 & 0.16 \\
\hline clock & 0.18 & 0.01 & 0.34 & 6.01 & 22.94 \\
\hline crydash & 0.12 & 0.41 & 0.33 & 3.93 & 15.03 \\
\hline foxk2 & 0.14 & 0.29 & 0.23 & 5.58 & 21.32 \\
\hline mbnl1 & 0.19 & 0.31 & 0.31 & 5.44 & 20.77 \\
\hline mrf4 & 0.09 & 0.29 & 0.40 & 0.70 & 2.67 \\
\hline mstn & 0.23 & 0.28 & 0.34 & 0.87 & 3.32 \\
\hline murf1 & 0.27 & 0.31 & 0.35 & 5.33 & 20.34 \\
\hline myf5 & 0.19 & 0.09 & 0.31 & 5.56 & 21.23 \\
\hline myoD & 0.13 & 0.42 & 0.45 & 5.73 & 21.90 \\
\hline myoG & 0.16 & 0.32 & 0.45 & 0.74 & 2.81 \\
\hline pdk4 & 0.16 & 0.34 & 0.31 & 5.96 & 22.78 \\
\hline pcna & 0.26 & 0.02 & 0.35 & 5.25 & 20.05 \\
\hline ucp3 & 0.05 & 0.95 & 0.39 & 1.16 & 4.45 \\
\hline
\end{tabular}

Note: Expression levels of clock genes and muscle-related genes are highlighted in bold while they displayed daily rhythmicity. The $P$ value is defined as the noise/signal ratio of the oscillation amplitude. Daily rhythmicity is indicated when $P$ value is less than 0.3

positive correlation to per2 and per3. Arntl2 also displayed a moderate positive correlation with per2 expression. Nr1d2 showed no correlation with other genes (Table 4).

\section{Daily expression of myogenic related genes and the correlation with the clock components in fast and slow muscles}

In fast muscles, mbnl1, mrf4, mstn, myf5, myoD, myoG and pcna displayed a daily rhythmic expression (Table 1 and Fig. 5), but only pcna had an acrophase during the dark phase $(\mathrm{ZT}=22.91 \mathrm{~h})$. In slow muscles, foxk2, mrf4, mstn, myf5 and pcna exhibited a daily rhythmic expression (Table 2 and Fig. 6). Mrf4 and mstn showed an acrophase during the light phase $(\mathrm{ZT}=2.67 \mathrm{~h}$ and $3.32 \mathrm{~h})$. In contrast, foxk2 $(\mathrm{ZT}=21.32 \mathrm{~h}), m y f 5(\mathrm{ZT}=21.23 \mathrm{~h})$ and pcna $(\mathrm{ZT}=20.05 \mathrm{~h})$ had an acrophase during the dark phase. 


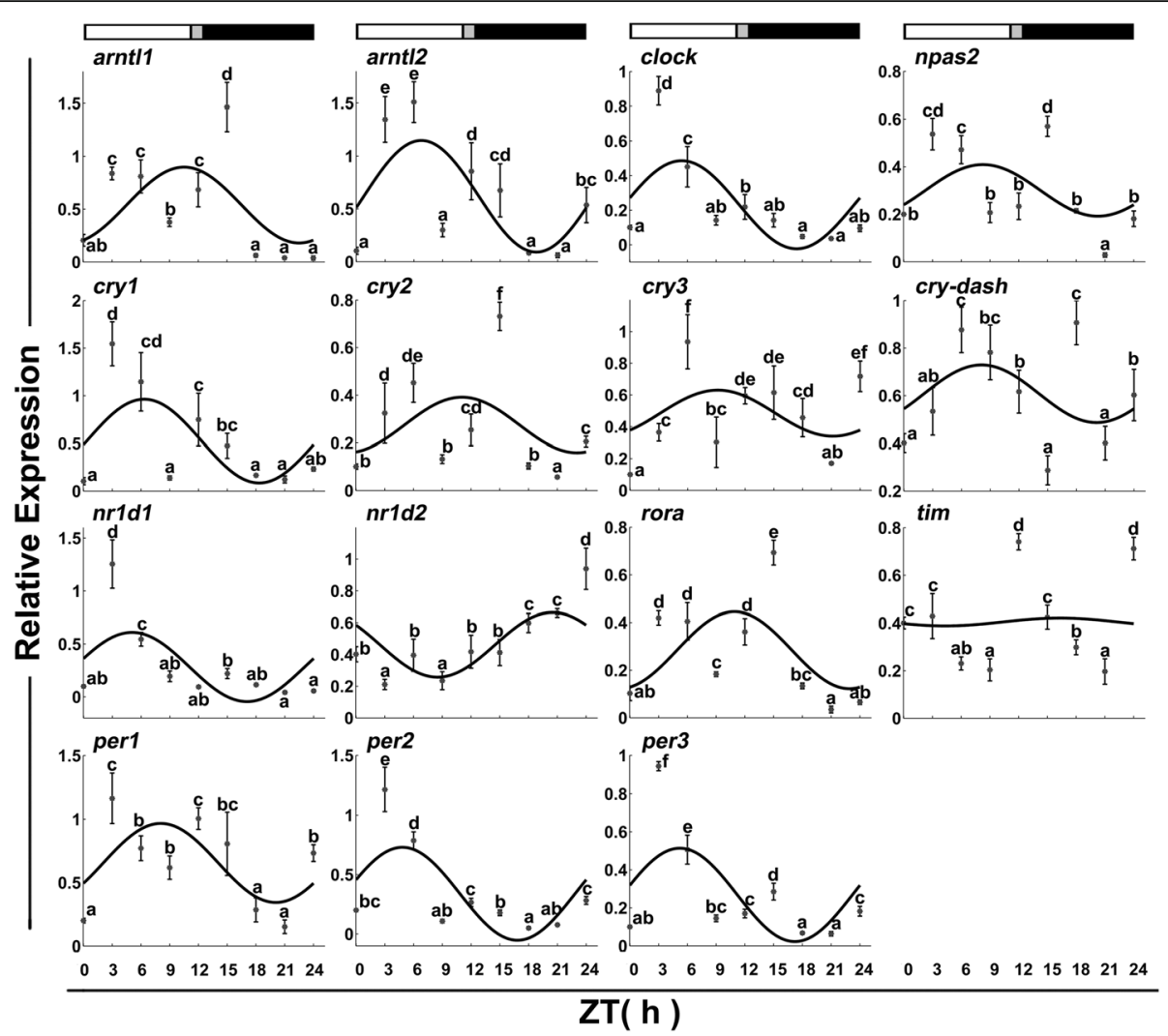

Fig. 3 Expression of clock genes in fast skeletal muscles during a daily cycle. The values are mean \pm SEM $(n=6)$ of the normalized transcript levels of each clock gene. Significant differences between time points are indicated by different lower-case letters. The line represents the periodic sinusoidal function of gene expression in a circadian cycle constructed from the periodicity parameters calculated using COSINOR. The photoperiod regime is represented by the composite block. White, black and gray, represent the light, dark and light-dark transition phases, respectively

The mRNA transcript levels of most myogenic related genes had either a positive or a negative correlation with the daily expression of clock genes in fast and slow muscles (Tables 5 and 6). In fast muscles, the transcript levels of pcna displayed a moderate negative correlation with arntl2, cry1 and per1 $(-0.8<r<-0.5)$. Mbnl1 showed a strong positive correlation with the daily expression of arntl2, cry1, nr1d1, per2, per3 and clock $(r>0.8)$. MyoG was also positively correlated with arntl2 and per2. In slow muscles, the transcript levels of pcna showed a moderate positive correlation with arntl2, cry 1 and per1. myf5, mrf4, pcna and mstn showed a strong positive correlation with cry3 and npas 2 in slow muscles. The foxk 2 gene also showed a strong correlation with transcriptional activators, such as arm arntl2.

\section{Discussion}

In the present study, we identified for the first time 15 clock genes, including four transcriptional activation factors (arntl1, arntl2, clock and npas2), eight transcriptional repressors (cry1, cry2, cry3, cry-dash, per1, per2, per3 and tim), and three orphan nuclear receptors ( $n r 1 d 1, n r 1 d 2$ and $r o r \alpha$ ) in Chinese perch skeletal muscles. As expected, some of the clock genes exhibited a robust oscillation during the light-dark cycle in the slow or fast skeletal muscle.

The full length cDNA sequences of several key clock genes, such as clock, cry1, per1 and $n r 1 d 2$, were cloned from Chinese perch. Silico structural analysis of the deduced amino acid sequences indicated that clock and per1 proteins contain the conserved PAS and bHLH domains [24]. These two domains are required for the circadian clock functions and are highly conserved in different species during evolution [25]. The transcriptional repressor cry1 has a typical DNA-photolyase and flavin adenine dinucleotide(FAD)-binding domains that are present in all cryptochrome genes [26, 27]. Together with photolyase DNA repair enzymes, FAD-binding domain containing proteins form the cryptochrome/ photolyase complex. This active complex has been used in blue light-induced gene expression to affect biological rhythm $[26,28,29]$. In nr1d2 protein, two core nuclear domains were also identified from its deduced amino acid sequence. The $n r 1 d 2$ binds to arntl1 and clock via a unique zinc finger structure domain to form a complex, which binds and blocks the protein complex formation by Circadian Locomotor Cycles [30, 31]. 


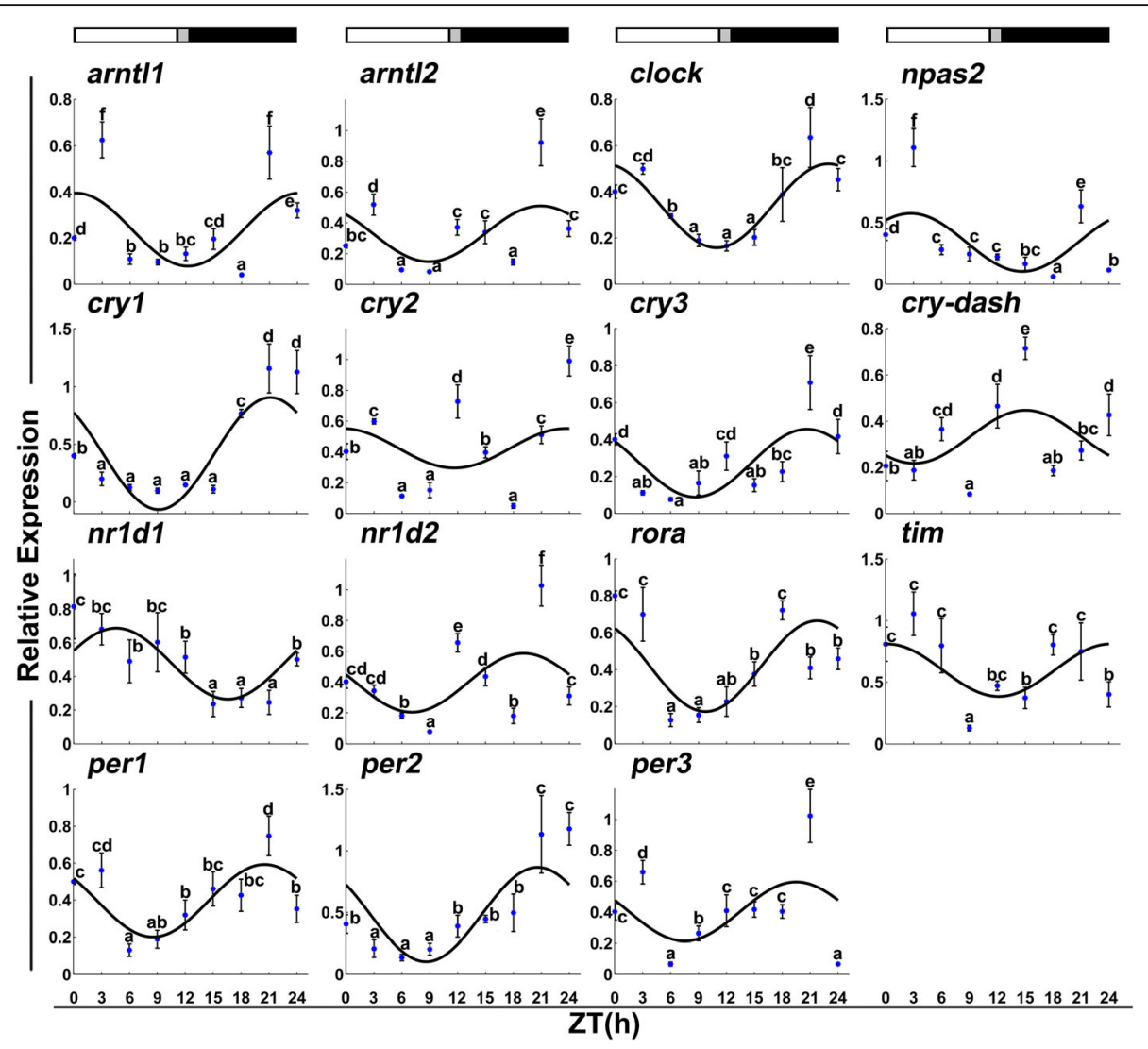

Fig. 4 Expression of clock genes in slow skeletal muscles during a daily cycle. The values are mean \pm SEM $(n=6)$ of the normalized transcript levels of each clock gene. Significant differences between time points are indicated by different lower-case letters. The line represents the periodic sinusoidal function of gene expression in a circadian cycle constructed from the periodicity parameters calculated using COSINOR. The photoperiod regime is represented by the composite block. White, black and gray, represent the light, dark and light-dark transition phases, respectively

The daily rhythmicity was observed in many clock genes in fast muscles of several species, indicating a potential regulatory function in muscle physiology and metabolism $([2,20,32]$, and [33]). However, the circadian clock gene expression in slow muscles has not been reported. In the study, we analyzed the arntl1 and arntl2 gene expression in Chinese perch and showed that they exhibited a light-biased expression in fast muscles. Several earlier reports in rainbow trout and mouse suggested that the photosensitivity profile in fast muscles is regulated by their homologous expression in either central or peripheral clocks $([10,34,35])$. However, their dark-biased expression in Chinese perch slow muscle is similar to that observed in Atlantic cod and zebrafish fast muscles. The correlation between arntl1/2 and clock/npas2 in Chinese perch slow muscles indicated that the mechanism underlying the transcriptional activation of the clock system may be similar to those reported from other fish species in slow muscles. Npas 2 which shares a high sequence homology with clock protein is able to substitute for clock function in the master brain clock and regulates the circadian rhythmicity in the brain. The antiphase profile between arntl and clock in Chinese perch fast muscles suggested that arntl may correlate with other bHLH-PAS factors in fish muscles.

Among the 3 period genes expressed in Chinese perch slow muscles, their dark-biased expression was in agreement with that reported from other fish species, such as goldfish, European sea bass and zebrafish [20, 28, 36, 37]. On the other hand, their light-biased expression in Chinese perch fast muscle is also consistent with the central and peripheral clocks in Senegalese sole [24]. The three period genes with the daily rhythmic expression also displayed a positive correlation with the $c r y 1$ gene, the only cryptochrome gene with the daily rhythmicity in Chinese perch fast muscle. Of the period and cry genes with the daily rhythmic expression in Chinese perch slow muscles, per1/2 showed the positive correlation with both cry1 and cry3. These results suggested that per may interact with cry to control the transcriptional activation and function in the circadian feedback loop.

Nr1d1, nr1d2 and ror are members of nuclear receptor family, which are involved in stabilizing the circadian 
Table 3 The expression correlations among different clock genes in fast muscle during a daily cycle

\begin{tabular}{|c|c|c|c|}
\hline Correlations & Gene & Gene & $r$ \\
\hline \multirow[t]{43}{*}{ Positive correlation } & arntl1 & $\operatorname{arnt} 12$ & +0.64 \\
\hline & arntl1 & cry1 & +0.58 \\
\hline & arntl1 & cry2 & +0.93 \\
\hline & arntl1 & npas2 & +0.88 \\
\hline & arntl1 & per1 & +0.66 \\
\hline & arntl1 & per3 & +0.53 \\
\hline & arntl1 & rora & +0.99 \\
\hline & $\operatorname{arnt} 12$ & cry 1 & +0.94 \\
\hline & arntl2 & cry2 & +0.61 \\
\hline & $\operatorname{arnt} 12$ & cry3 & +0.66 \\
\hline & arntl2 & npas2 & +0.76 \\
\hline & arntl2 & $\mathrm{nr} 1 \mathrm{~d} 1$ & +0.74 \\
\hline & arntl2 & per1 & +0.83 \\
\hline & arntl2 & per2 & +0.86 \\
\hline & arntl2 & per3 & +0.83 \\
\hline & arntl2 & clock & +0.82 \\
\hline & $\operatorname{arnt} 12$ & rora & +0.64 \\
\hline & clock & npas2 & +0.68 \\
\hline & clock & per1 & +0.72 \\
\hline & clock & per2 & +0.98 \\
\hline & clock & per3 & +0.98 \\
\hline & clock & nr1d1 & +0.98 \\
\hline & clock & cry 1 & +0.94 \\
\hline & cry 1 & npas2 & +0.74 \\
\hline & cry1 & nr1d1 & +0.89 \\
\hline & cry 1 & per1 & +0.79 \\
\hline & cry1 & per2 & +0.94 \\
\hline & cry 1 & per3 & +0.93 \\
\hline & cry 1 & rora & +0.60 \\
\hline & cry2 & cry3 & +0.60 \\
\hline & cry2 & npas2 & +0.87 \\
\hline & cry2 & per1 & +0.58 \\
\hline & cry2 & rora & +0.94 \\
\hline & cry3 & per1 & +0.54 \\
\hline & npas2 & nr1d1 & +0.69 \\
\hline & npas2 & per1 & +0.69 \\
\hline & npas2 & per2 & +0.66 \\
\hline & npas2 & per3 & +0.76 \\
\hline & npas2 & rora & +0.90 \\
\hline & nr1d1 & per1 & +0.63 \\
\hline & nr1d1 & per2 & +0.95 \\
\hline & $\mathrm{nr} 1 \mathrm{~d} 1$ & per3 & +0.98 \\
\hline & per1 & tim & +0.50 \\
\hline
\end{tabular}

Table 3 The expression correlations among different clock genes in fast muscle during a daily cycle (Continued)

\begin{tabular}{|c|c|c|c|}
\hline & per1 & per2 & +0.68 \\
\hline & per1 & per3 & +0.72 \\
\hline & per1 & rora & +0.67 \\
\hline & per2 & per3 & +0.97 \\
\hline & per3 & rora & +0.53 \\
\hline \multirow[t]{5}{*}{ Negative correlation } & arntl1 & $\mathrm{nr} 1 \mathrm{~d} 2$ & -0.55 \\
\hline & clock & $\mathrm{nr} 1 \mathrm{~d} 2$ & -0.55 \\
\hline & npas2 & $\mathrm{nr} 1 \mathrm{~d} 2$ & -0.52 \\
\hline & $\mathrm{nr} 1 \mathrm{~d} 1$ & $\mathrm{nr} 1 \mathrm{~d} 2$ & -0.56 \\
\hline & $\mathrm{nr} 1 \mathrm{~d} 2$ & rora & -0.52 \\
\hline
\end{tabular}

clock loop [20,38-40]. Nr1d1 and $n r 1 d 2$ were identified as the constitutive transcriptional repressors of arntl1, whereas ror $\alpha$ is the arntl1 transcriptional activator [2, 41]. In addition, $n r 1 d 1$ was considered to be interwoven into the core clock mechanism via downregulating the clock expression. As reported in mammals, Npas 2 expression was repressed by these nuclear receptors [40, 42]. In this study, the three nuclear receptors displayed a daily rhythmic expression in Chinese perch fast muscles and $n r 1 d 2$ exhibited a negative correlation with the expression of rora gene. This is reflected in their tight regulation with the circadian mechanism. Nr1d2 also showed a negative correlation with clock and npas2. Therefore, it is possible that $n r l d 2$ may function by repressing npas 2 and clock expression in fast muscles. However, $n r 1 d 2$ had no daily rhythmic expression in Chinese perch slow muscles and $n r 1 d 1$ showed a direct relationship with the rora expression. It could suggest that Chinese perch slow muscles may have a different circadian mechanism in maintaining the stabilization loop.

In this study, the transcription levels of eleven genes related to myogenesis during the daily cycle were investigated. The data revealed that seven genes had a daily rhythmic expression in fast muscles and five in slow muscles. Myogenic regulatory factors(MRFs) (such as $m y o D, m y f 5, m r f 4$ and $m y o G$ ), belong to the same class of helix-loop-helix transcription factors that play distinct and overlapping roles in regulating muscle development and growth [43, 44]. It has been reported that the circadian regulation of $m y o D$ expression by lock/arntl was crucial for the skeletal muscle phenotype and function in mouse [32]. Our study confirmed that myoD in Chinese perch fast muscles exhibited a typical daily rhythmicity. Based on our observation, it is possible that the 
Table 4 The expression correlations among different clock genes in slow muscle during a daily cycle

\begin{tabular}{|c|c|c|c|}
\hline Correlations & Gene & Gene & $r$ \\
\hline \multirow[t]{40}{*}{ Positive correlation } & arntl1 & arntl2 & $\overline{0.84}$ \\
\hline & arntl1 & cry2 & 0.51 \\
\hline & arntl1 & clock & 0.77 \\
\hline & arntl1 & npas2 & 0.84 \\
\hline & arntl1 & $\mathrm{nr} 1 \mathrm{~d} 2$ & 0.55 \\
\hline & arntl1 & per1 & 0.74 \\
\hline & arntl1 & per3 & 0.68 \\
\hline & arntl2 & clock & 0.70 \\
\hline & arntl2 & cry1 & 0.53 \\
\hline & $\operatorname{arnt} 12$ & cry2 & 0.50 \\
\hline & arntl2 & cry3 & 0.73 \\
\hline & arntl2 & npas2 & 0.56 \\
\hline & arntl2 & $\mathrm{nr} 1 \mathrm{~d} 2$ & 0.89 \\
\hline & $\operatorname{arnt} 12$ & per1 & 0.85 \\
\hline & arntl2 & per2 & 0.62 \\
\hline & arntl2 & per3 & 0.84 \\
\hline & clock & cry1 & 0.75 \\
\hline & clock & cry3 & 0.62 \\
\hline & clock & npas2 & 0.56 \\
\hline & clock & per1 & 0.74 \\
\hline & clock & per2 & 0.61 \\
\hline & clock & per3 & 0.58 \\
\hline & clock & rora & 0.54 \\
\hline & clock & tim & 0.62 \\
\hline & cry 1 & per1 & 0.51 \\
\hline & cry1 & per2 & 0.92 \\
\hline & cry2 & per2 & 0.58 \\
\hline & cry3 & $\mathrm{nr} 1 \mathrm{~d} 2$ & 0.78 \\
\hline & cry3 & per1 & 0.64 \\
\hline & cry3 & per2 & 0.83 \\
\hline & cry3 & per3 & 0.55 \\
\hline & npas2 & per1 & 0.54 \\
\hline & npas2 & per3 & 0.62 \\
\hline & npas2 & tim & 0.63 \\
\hline & $\mathrm{nr} 1 \mathrm{~d} 2$ & per1 & 0.72 \\
\hline & $\mathrm{nr} 1 \mathrm{~d} 2$ & per2 & 0.56 \\
\hline & per1 & per2 & 0.51 \\
\hline & per1 & per3 & 0.88 \\
\hline & per1 & rora & 0.61 \\
\hline & rora & tim & 0.61 \\
\hline
\end{tabular}

Note: Only correlations with $r>+0.5$ or $r<-0.5$ and including at least one gene with significant daily rhythmicity are shown in this table. The following values were set to define the degree of correlation: data are moderately correlated if $0.5<r<0.79$ and there is a strong correlation when $r \geq 0.80$ which are highlighted in bold circadian regulation of Chinese perch myoD may function in a similar way as reported in mouse. In contrast, we have not obtained any direct evidence for circadian expression of $m y o D$ in Chinese perch slow muscles. Therefore, it is possible that the differentially expressed MRFs may result from the lineage-specific differences by clock genes. However, our work demonstrated that one of the MRFs, mrf4, in Chinese perch slow muscles exhibited a rhythmic expression pattern similar to that described for $m y o D$ in fast muscles, suggesting that mrf4 may have a potential function in the maintenance of muscle phenotype and function.

\section{Conclusion}

In this study, we assayed the possible correlation of a functional clock system in Chinese perch slow and fast skeletal muscles. We demonstrated that 10 clock genes and 7 genes related to myogenesis exhibited the daily rhythmicity in fast muscles of Chinese perch. The 11 clock genes and 5 genes related to myogenesis have the daily rhythmicity in slow muscles (Fig. 7). The circadian expression of mrf4, myf5, mstn, and pcna may either positively or negatively regulate the transcription of the clock genes in both types of muscles. It is plausible that muscle type-specific maintenance and function is regulated by the core clock genes. This is based on the evidence of daily rhythmicity and apparent correlation of gene expression of clock genes and genes related to myogenesis. Taken together, our data provide new information on the rhythmic expression of clock genes and a better understanding of the circadian clocks in fish muscle phenotype maintaining and function.

\section{Methods}

Daily rhythm experiment

Adult Chinese perch (body weight $450 \pm 10$ g) were stocked in $250 \mathrm{~m}^{3}$ tanks. Fifteen testing fishes were kept in each tank and a total of six tanks were used in the experiment. To liminate the fish disturbance during sampling, the fish were fed at the same time each day. During the experiment, water temperature was kept at $25 \pm 0.8{ }^{\circ} \mathrm{C}$, dissolved oxygen at $85 \pm 2 \%$ and the light intensity of the water surface at $0.84 \mathrm{~W}^{*} \mathrm{~m}^{-2}(200 \mathrm{~lx})$. The testing fishes were acclimated to the above described conditions for 2 weeks during a daily lightdark cycle before sample collection. Six individuals were randomly collected from the each tank in every three hours until 24 h (Zeitgeber time: ZT0, 3, 6, 9, 12, 15, 18, 21 and 24). Sampling of the light treatment at the different time points was basically followed as described by Lazada [2]. Briefly, samples at ZT0 were collected when the light reached to a maximum intensity, the samples at ZT24 were collected when it transited to the light phase; The ZT12 samples were collected at approximately 


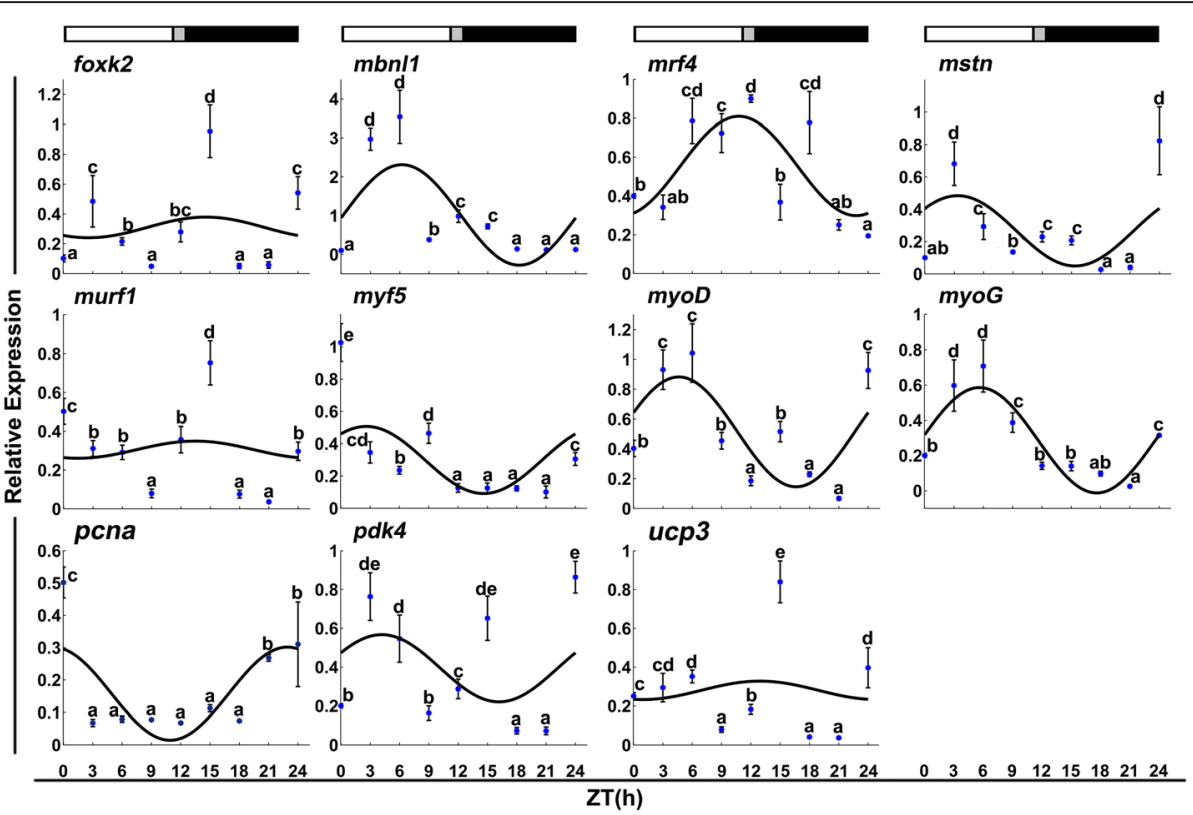

Fig. 5 Expression of myogenesis-related genes in fast skeletal muscles during a daily cycle. The values are mean \pm SEM $(n=6)$ of the normalized transcript levels of each clock gene. Significant differences between time points are indicated by different letter notations. The line represents the periodic sinusoidal function of gene expression in a circadian cycle constructed from the periodicity parameters calculated using COSINOR. The photoperiod regime is represented by the composite block above the graph. White, black and gray represent the light, the dark and the light-dark transition phases, respectively

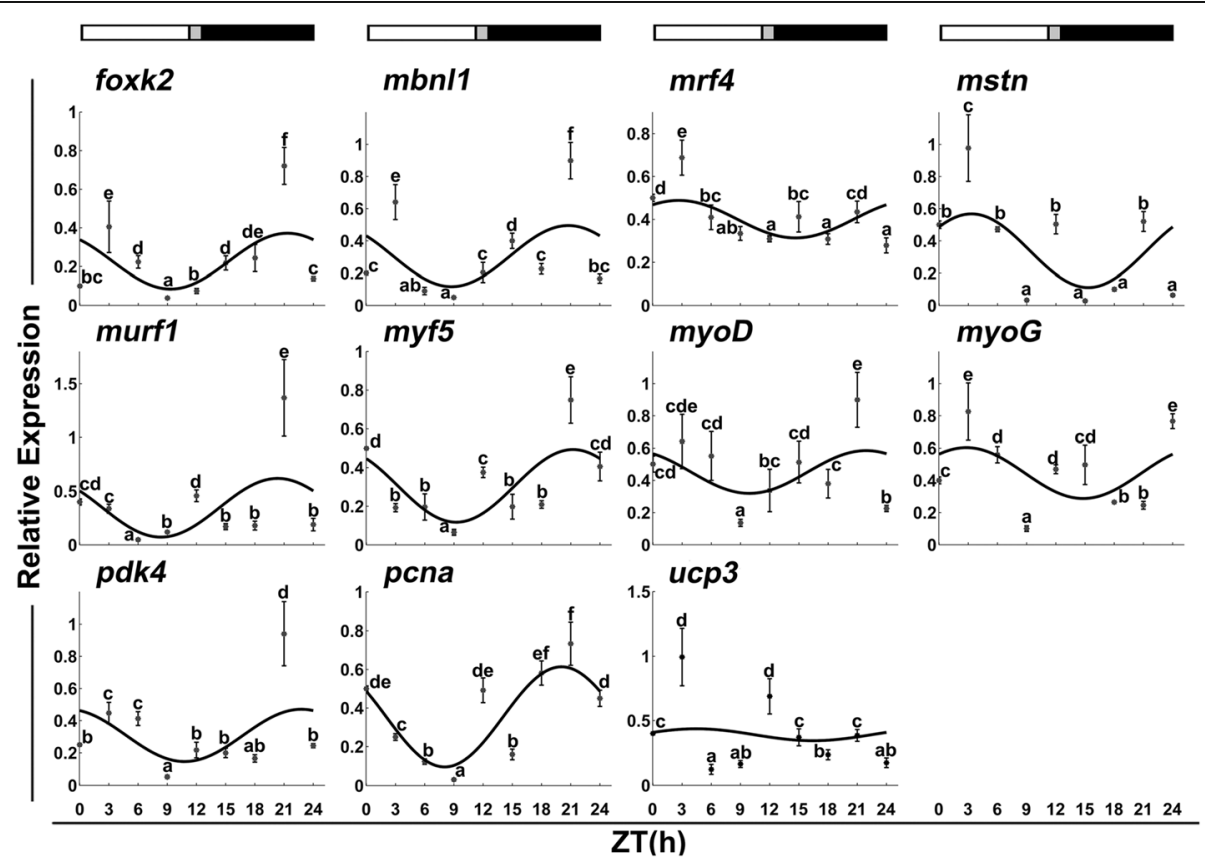

Fig. 6 Expression of myogenesis-related genes in slow skeletal muscles during a daily cycle. The values are mean \pm SEM $(n=6)$ of the normalized transcript levels of each clock gene. Significant differences between time points are indicated by different letter notations. The line represents the periodic sinusoidal function of gene expression in a circadian cycle constructed from the periodicity parameters calculated using COSINOR. The photoperiod regime is represented by the composite block above the graph. White, black and gray represent the light, the dark and the light-dark transition phases, respectively 
Table 5 Correlation of expression levels of rhythmic clock and muscle-related genes in the fast muscle

\begin{tabular}{cccccccc}
\hline $\begin{array}{c}\text { Clock } \\
\text { gene }\end{array}$ & mbn11 & mrf4 & mstn & myf5 & myoD & myoG & pcna \\
\hline arnt11 & $\mathbf{0 . 5 3}$ & 0.11 & 0.09 & -0.24 & 0.31 & 0.30 & -0.49 \\
arnt12 & $\mathbf{0 . 9 4}$ & 0.20 & $\mathbf{0 . 5 3}$ & -0.23 & $\mathbf{0 . 7 4}$ & $\mathbf{0 . 8 0}$ & $\mathbf{- 0 . 5 1}$ \\
cry1 & $\mathbf{0 . 9 3}$ & 0.14 & 0.48 & -0.20 & $\mathbf{0 . 6 1}$ & $\mathbf{0 . 7 3}$ & $\mathbf{- 0 . 5 1}$ \\
nrld1 & $\mathbf{0 . 8 2}$ & -0.08 & 0.49 & 0.00 & $\mathbf{0 . 6 2}$ & $\mathbf{0 . 7 4}$ & -0.40 \\
nr1d2 & -0.49 & -0.40 & 0.24 & -0.25 & -0.06 & -0.41 & 0.41 \\
per1 & $\mathbf{0 . 6 3}$ & 0.15 & $\mathbf{0 . 6 5}$ & -0.29 & $\mathbf{0 . 5 6}$ & $\mathbf{0 . 5 6}$ & $\mathbf{- 0 . 5 9}$ \\
per2 & $\mathbf{0 . 9 0}$ & -0.07 & $\mathbf{0 . 6 1}$ & 0.02 & $\mathbf{0 . 7 4}$ & $\mathbf{0 . 8 2}$ & -0.30 \\
per3 & $\mathbf{0 . 8 6}$ & -0.12 & $\mathbf{0 . 5 9}$ & -0.06 & $\mathbf{0 . 7 1}$ & $\mathbf{0 . 7 7}$ & -0.40 \\
ror $\alpha$ & $\mathbf{0 . 5 3}$ & 0.17 & 0.10 & -0.31 & 0.30 & 0.28 & $\mathbf{- 0 . 5 5}$ \\
clock & $\mathbf{0 . 8 6}$ & -0.01 & $\mathbf{0 . 5 3}$ & -0.01 & $\mathbf{0 . 6 3}$ & $\mathbf{0 . 7 7}$ & -0.40 \\
\hline
\end{tabular}

Note: The following values were set to define the degree of correlation: data are considered to be moderately correlated if $0.5<r<0.79$ or $-0.79<r<-0.5$ and there is a strong correlation when $r \geq 0.80$. And moderate correlation is marked in bold and strong correlation in red color

20 min later, while samples of ZT0-9 and ZT15-24 were collected at the time between the light and dark. The fast muscle was sampled from the dorsal muscle tissue, and slow muscle was collected under the body skin [16]. All of the collected muscle samples were washed with cold and sterilized $1 \times$ PBS to remove contaminating blood and then immediately stored in liquid nitrogen at $-80{ }^{\circ} \mathrm{C}$ for total RNA extraction.
Molecular cloning of Chinese perch clock genes

To amplify the cDNA fragments of the clock genes, the primers were designed based on the assembled EST sequences of the Chinese perch muscle database (accession nos: SRX1738860) or the clock gene sequences from several-related fish species (Table 1). The full length cDNAs of the four clock genes were amplified with the SMART RACE cDNA Amplification Kit

Table 6 Correlation of expression levels of rhythmic clock and muscle-related genes in the slow muscle

\begin{tabular}{cccccc}
\hline $\begin{array}{c}\text { Clock } \\
\text { genes }\end{array}$ & foxk2 & mrf4 & mstn & myf5 & pcna \\
\hline arnt11 & $\mathbf{0 . 7 6}$ & $\mathbf{0 . 6 7}$ & $\mathbf{0 . 6 4}$ & 0.47 & 0.28 \\
arnt12 & $\mathbf{0 . 8 4}$ & 0.34 & 0.44 & $\mathbf{0 . 7 6}$ & $\mathbf{0 . 5 9}$ \\
cry1 & $\mathbf{0 . 5 0}$ & -0.27 & -0.16 & $\mathbf{0 . 6 8}$ & $\mathbf{0 . 7 6}$ \\
cry3 & $\mathbf{0 . 5 1}$ & -0.16 & 0.03 & $\mathbf{0 . 9 5}$ & $\mathbf{0 . 8 2}$ \\
npas2 & $\mathbf{0 . 5 8}$ & $\mathbf{0 . 9 1}$ & $\mathbf{0 . 8 7}$ & 0.18 & 0.02 \\
nrld1 & -0.45 & 0.41 & 0.44 & -0.12 & -0.25 \\
per1 & $\mathbf{0 . 7 6}$ & 0.47 & 0.38 & $\mathbf{0 . 6 8}$ & $\mathbf{0 . 6 6}$ \\
per2 & 0.44 & -0.33 & -0.23 & $\mathbf{0 . 7 3}$ & $\mathbf{0 . 6 8}$ \\
ror & 0.18 & 0.45 & 0.27 & 0.23 & 0.48 \\
tim & $\mathbf{0 . 5 2}$ & $\mathbf{0 . 6 8}$ & $\mathbf{0 . 7 6}$ & 0.25 & 0.36 \\
clock & $\mathbf{0 . 7 9}$ & 0.41 & 0.42 & $\mathbf{0 . 6 5}$ & $\mathbf{0 . 6 2}$ \\
\hline
\end{tabular}

Note: The following values were set to define the degree of correlation: data are considered to be moderately correlated if $0.5<r<0.79$ or $-0.79<r<-0.5$ and there is a strong correlation when $r \geq 0.80$. And moderate correlation is marked in bold and strong correlation in red color 


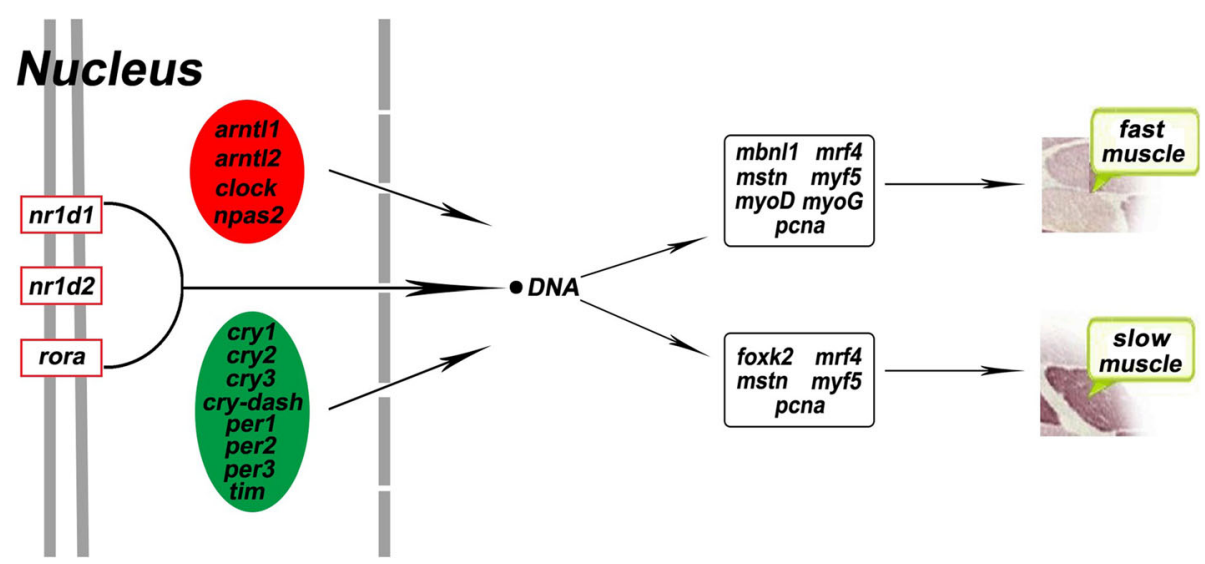

Fig. 7 Molecular components of the clock system identified in fast and slow skeletal muscles of Chinese Perch and myogenic genes with daily rhythmic expression. The green and red oval represent genes involved in the peripheral clock components in Chinese Perch skeletal muscles, which is related with the muscle fiber. They comprise members of the transcriptional activator arm (in red: arnt/1, arnt/2, clock and npas2), transcriptional repressor arm (in green: cry 1, cry2, cry3, cry-dash, per1, per2, per3 and tim) and nuclei (in nucleus: nr1d1, nr1d2 and rora). The daily rhythmicity of $m b n / 1, m r f 4, m s t n, m y f 5, m y o D$, myoG and pcna play a crucial role in fast muscle specification, and foxk2, mrf4, mstn, myf5 and pcna play an important role in terminal slow muscle differentiation

according to the manufacture's instruction (Clontech, Palo Alto, CA, USA). Specific nested PCR primers were designed based on the cloned partial sequences (Table 1). For 5' RACE amplification, the protocols were conducted as follows: 35 cycles of $94{ }^{\circ} \mathrm{C}$ for $30 \mathrm{~s}, 60{ }^{\circ} \mathrm{C}$ for $30 \mathrm{~s}$ and $72^{\circ} \mathrm{C}$ for $1 \mathrm{~min}$. For $3^{\prime}$-RACE, two amplifications were conducted at the same parameters as $5^{\prime}$ RACE the amplification described above.

\section{Bioinformatic analysis of the clock genes}

The cDNA fragment identity was confirmed with BLAST (http://blast.ncbi.nlm.nih.gov) and the deduced amino acid sequences were obtained using the ExPASy Proteomics Server (http://www.expasy.ch). The complete amino acid sequences of the clock, cry 1 , per 1 and $n r 1 d 2$ domains were analyzed through UniProt (http://www.uniprot.org) and the ExPASy proteomics Server (http://www.expasy.ch). The clock gene sequences of other teleosts were obtained from the NCBI databases and the protein accession numbers are listed in Additional file 2.

\section{Gene expression analysis}

Total RNAs were isolated from Chinese perch muscles using the TRIzol ${ }^{\mathrm{R}}$ Reagent (Invitrogen, USA). The RNA samples were treated with RNAse-free DNAse I (Promega, USA) in the presence of RNAse inhibitor (Sigma, China Branch), and then precipitated with ethanol. The obtained RNA was reversely transcribed with Super-Script III RNase H-Reverse Transcriptase (Invitrogen, USA) following the manufacturer's instruction. For a negative control, no cDNA sample was added in the PCR reaction.
Primers for the qRT-PCR assays were designed using the software Primer 5.0 (Table 7). The reverse transcribed cDNAs from skeletal muscles were used as templates for qRT-PCR assays with SYBR Green PCR reaction kit (Stratagene, Shanghai, China). The qRT-PCR amplification reaction was carried out using the Stratagene Mx3005 system (Stratagene, CA, USA). A total volume of $25 \mu \mathrm{L}$ reaction was used for the qRT-PCR assays, containing $1 \mu \mathrm{L}$ cDNA templates, $12.5 \mu \mathrm{L}$ SYBR Green mix, and $1 \mu \mathrm{mol} / \mathrm{L}$ each of forward and reverse primers. The reaction protocol was used as the standard cycling of the qPCR. Each product identity was verified by dideoxy-mediated chain termination sequencing at Sangon Biotechnology Inc. (Shanghai, China). The relative expression ratio $(R)$ of target mRNA was calculated by $\mathrm{R}=2^{-\Delta \Delta \mathrm{Ct}}[45,46]$, where $\mathrm{Ct}$ is the cycle threshold. The basic equation employed was $\Delta \Delta \mathrm{Ct}=(\mathrm{Ct}$ target gene $-\mathrm{Ct}$ housekeeping gene $)$ experiment $-(\mathrm{Ct}$ target gene $-\mathrm{Ct}$ housekeeping gene) control. The treanscriptional levels of selected muscle-related genes in Chinese perch fast and slow muscles during a daily cycle were also quantitatively assayed using the same qRT-PCR protocol.

The stability of transcription of reference genes was assayed with GeNorm system and total six reference genes were analyzed including Glyceraldehyde-3phosphate dehydrogenase (GAPDH), $\beta$-actin, $18 \mathrm{~S}$ rRNA gene, hypoxanthine phosphoribosyltransferase 1-like (hprt1), epinephelus coioides ribosomal protein S29 (rps29) and ribosomal protein L13 (rpl13) [47-49]. GeNorm analysis revealed that rpl13 was the most stable control gene in skeletal muscles (geNorm stability value $M=0.28$ ). The geometric average of these genes were measured by absolute quantification within all samples 
Table 7 Primers used for genes cloning and quantitative real-time $P C R$

\begin{tabular}{|c|c|c|c|c|c|}
\hline Primer name & Sequence $\left(5^{\prime}-3^{\prime}\right)$ & Items & \multirow{3}{*}{$\operatorname{Tim}$} & F: GGTGGGTTCTACCTGGACTTCC & \multirow{3}{*}{ RT-PCR } \\
\hline 3'-RACE outer & R:CTGATCTAGAGGTACCGGATCC & $3^{\prime}-$ RACE & & R: TGAAGGAGCAGTACGGGAAGAA & \\
\hline Clock 3'-RACE inner & F:AGACGGCTGTAGTGGCTC & 3'-RACE & & F: GAAGGCTACAGCAAAGACGGA & \\
\hline Clock 3'-RACE inner & F:AGACGGCTGTAGTGGCTC & 3'-RACE & \multirow[t]{2}{*}{ Foxk2 } & R:CTGGCACTTCAGAATGACGGT & \multirow[t]{2}{*}{ RT-PCR } \\
\hline 5'-RACE outer & $\mathrm{F}: \mathrm{GACTCGAGTCGACATCG}$ & $5^{\prime}$-RACE & & F: CCTGAGGTGTCTCGGCAAAA & \\
\hline Cry1 5'-RACE inner & R: TTGGCATTCATTCTGGGACG & 5'-RACE & \multirow[t]{2}{*}{ Mbnl1 } & R: TGAGCGATGTTGTCTGGAATG & \multirow[t]{2}{*}{ RT-PCR } \\
\hline Cry1 5'-RACE inner & R: GGTCTGGAACCGTTTGTAGG & $5^{\prime}-$ RACE & & F: AGGTGGACAACGGACGGG & \\
\hline Cry1 3'-RACE inner & F: TCAAGGAGACTGGCAAAGCG & 3'-RACE & \multirow[t]{2}{*}{ Mrf4 } & R: CTITAGGTGGGGAGGAGGGT & \multirow[t]{2}{*}{ RT-PCR } \\
\hline Cry1 3'-RACE inner & F: CCACAAGCCAGCATCAGCAC & 3'-RACE & & F: CCGACCTCTGCTGACCATTC & \\
\hline Per1 5'-RACE inner & R: ATTTAGAGTGCTGGCGTGGC & $5^{\prime}$-RACE & \multirow[t]{2}{*}{ Mstn } & R: GACGCAGAAGACTCACTGGTT & \multirow[t]{2}{*}{ RT-PCR } \\
\hline Per1 5'-RACE inner & R: GGGCGAACCTTCAGATCCTG & 5'-RACE & & F:GCACATACGCATCCGCTCCCT & \\
\hline Per1 3'-RACE inner & F: GAGAACGGTGAAACAAATGA & $3^{\prime}$-RACE & \multirow[t]{2}{*}{ Murf1 } & R:GTCACGGCCAAGTCATTTCCA & \multirow[t]{2}{*}{ RT-PCR } \\
\hline Per1 3'-RACE inner & F: ACGCTTCACCGAGGAACAGA & 3'-RACE & & F: TCCAGGAACCCCTACCACTACT & \\
\hline Nr1d2 5'-RACE inner & R: CAGTCTGAAGGGGCAGTGGT & 5'-RACE & \multirow[t]{2}{*}{ Myf5 } & R: CACTTCGGCTCTTTGGTGTCTT & \multirow[t]{2}{*}{ RT-PCR } \\
\hline Nr1d2 5'-RACE inner & R: GACTGGTAGCTGCCGTTGGA & 5'-RACE & & F:AGGTCAACCACGCTTTCGAG & \\
\hline Nr1d2 3'-RACE inner & F: AGTGCCGCTTCAAGAAATGC & 3'-RACE & \multirow[t]{2}{*}{ myoD } & R:GTITCCACCTGCTCCCGTA & \multirow[t]{2}{*}{ RT-PCR } \\
\hline Nr1d2 3'-RACE inner & F: GGAGATGAGCCTCTTCACTGC & 3'-RACE & & F:CAACGACGCCTITGAGACCCTG & \\
\hline Arntl1 & F: GGCTATCCCTACTCCAACCAG & RT-PCR & \multirow[t]{2}{*}{ myoG } & R:GTCCGAATCCCCGCTGTAGTGT & \multirow[t]{2}{*}{ RT-PCR } \\
\hline Arntl2 & R: TTGCTGGGGCTGCTGGAA & RT-PCR & & F: GGTGTTGGAGTCGGGGTGA & \\
\hline & F: AGGGACCCAAATCGCAAATG & & \multirow[t]{2}{*}{ Pdk4 } & R: TGGTAACCGTCTTCCTTTTGC & \multirow[t]{2}{*}{ RT-PCR } \\
\hline Clock & R: TGTGGGGAAACAAGGGGAC & RT-PCR & & F: CTCTGGTGAACATCCGTAATCG & \\
\hline & F: TGCTGGAGGCTCTGGATGG & & \multirow[t]{2}{*}{ Pena } & R:ATGGGCTGGGTTCACGCT & \multirow[t]{2}{*}{ RT-PCR } \\
\hline Npas2 & R: GGTTCTGGTCCACTAAGTCCGTC & RT-PCR & & F: GGACGAGGCGGTCACTATTG & \\
\hline & F: CAGATAGCGAGTTCAGCCAAGA & & \multirow[t]{2}{*}{ Ucp3 } & R: CTGAGGGTGACGGTCTTGGA & \multirow[t]{2}{*}{ RT-PCR } \\
\hline Cry1 & R: TGGAGAATGAAGGAGCGATGA & RT-PCR & & F: GTATCGGGGAGCGTTTGG & \\
\hline & F: GAATGCCAACTCACTGCTCG & & \multirow[t]{2}{*}{ Rpl-13 } & R: AGTCCTGCCACCAGTCCGT & \multirow{2}{*}{$\begin{array}{l}\text { internal } \\
\text { reference }\end{array}$} \\
\hline Cry2 & R: CGAAGCAGGGGTTGTTGG & RT-PCR & & F:CACAAGAAGGAGAAGGCTCGGGT & \\
\hline & F: GAGAAAAGCGTGGGTGGC & & $\beta$-actin & R: TTTGGCTCTCTTGGCACGGAT & internal \\
\hline Cry3 & R: CTTGCGGTAGAGGTCTGTGAG & RT-PCR & & F:TGCGTGACATCAAGGAGAAGC & \\
\hline & F: ATCTTGAAGGACTACCCGAACC & & & R:GAGGAAGGAAGGCTGGAAGAG & \\
\hline Cry-dash & R: GCTGCCCTCTGCGTGGTTA & RT-PCR & hprt1 & F:CATACCAAAGCATTACGCAGAAG & internal \\
\hline & F: GCCCTGGACCCTCAGCACT & & & & \\
\hline Per1 & R: CCTCTATCCCGATGTTGTTTGG & RT-PCR & & R:CACCTCGAATCCTACAAAGTCCG & \\
\hline & F: CAACAAACTCATCCTCCTGGC & & rps29 & F:TCACCCCAGAAAATTCGGACAGG & internal \\
\hline Per2 & R: CGGTGGGTAAACAGGGTAGATT & RT-PCR & & R:GTATTACGGATCAGACCGTGTC & \\
\hline & F: TGGTAACGAGTCGCAAGGC & & GAPDH & F:ATCAAGGAAGCGGTGAAGAAGG & \\
\hline Per3 & R: TCACCAGACTGAAGGCGTTAGA & RT-PCR & & & reference \\
\hline & F: CAAAGCCGAGTGAAGGACAG & & & R:CGAAGATGGAGGAGTGGGTGTC & \\
\hline Nr1d1 & R: GGGTTATCGCTCTGGTTGG & RT-PCR & $18 \mathrm{~S}$ rRNA & F:GGAATGAGCGTATCCTAAACCC & internal \\
\hline & F: GCCGTGGTGCTGGTGTCTG & & & & \\
\hline $\mathrm{Nr} 1 \mathrm{~d} 2$ & R: TTGTTGAGCGTTCGCAGGTC & RT-PCR & & R:CTCCCGAGATCCAACTACAAGC & \\
\hline
\end{tabular}

Table 7 Primers used for genes cloning and quantitative real-time PCR (Continued)
F:TCTCCCCATGTGGACCCTC R: GGTGCGGTCCTTCACATCG
RT-PCR 
then calculated by one-way ANOVA procedures and gene expression values are displayed as arbitrary units.

\section{Statistical analysis}

The transcriptional expression levels of the clock and muscle-related genes at each time points were analyzed with the Sigma plot and then were calculated by one-way ANOVA procedures using SPSS software. To compare the difference between the control and experimental groups, Duncan's multiple range tests were used for the analysis. The differences were considered to be statistically significant when the $P$ value was less than 0.05 . Data are shown as means \pm SE $(n=6)$.

The daily rhythmicity in relation to the expression of the clock and muscle-related genes was assayed with Matlab 7.0 followed as described by earlier studies [2, 37]. To perform a COSINOR analysis, the formula $f(\mathrm{t})=\mathrm{M}+$ $A \cos (\mathrm{t} / \mathrm{pi} / 12-\phi)$ was used, where $f(\mathrm{t})$ stands for the gene expression level at a given time, mesor $(\mathrm{M})$ stands for the mean value, A stands for is the oscillation amplitude, $t$ is the time in hours and $\phi$ stands for the acrophase. The $P$ value was defined by the noise/signal of the amplitude (SE(A)/A) and if $P$ Value $<0.3$, the expression levels could considered to display daily rhythmicity $[2,37]$. Correlation between the clock and muscle-related gene expression was assayed with Pearson's correlation test $(r)$.

\section{Additional files}

Additional file 1: The 15 clock genes sequences of Chinese perch Genbank accession number. (DOC 36 kb)

Additional file 2: The clock genes protein sequences of other teleosts Genbank accession number. (DOC 39 kb)

\section{Abbreviations}

bHLH: Basic-helix-loop-helix; FAD: Flavin adenine dinucleotide; GAPDH: Glyceraldehyde-3-phosphate dehydrogenase; L. crocea: Larimichthys crocea; MFMR: Multifunctional mosaic region; MRFs: Myogenic regulatory factors; MS-222: Tricaine methanesulfonate; ORF: Open reading frame; PAS: Per-Arnt-Ser; UTR: Untranslated regions; ZT: Zeitgeber time

\section{Acknowledgments}

We thank Dr. Shaojun Du from University of Maryland USA for proofreading and instruction during the manuscript preparation and The Collaborative Innovation Center for Efficient and Health Production of Fisheries, Hunan Province for supporting and assistance with the fish.

\section{Funding}

W.Y.C. is funded by the Nature and Science Foundation of China for the skeletal muscle gene cloning and expression analysis (No. 31472256); J.S.Z is also funded by the Nature and Science Foundation of China for the skeletal muscle gene and function analysis (no 31230076 and No.31572592); J.C is funded by the Nature and Science Foundation of China for the clock gene identification (no 31502149). The funding bodies did not have a role in the design of the study, data collection, analysis, interpretation of data, writing the manuscript, nor the decision to publish.

\section{Availability of data and materials}

Chinese perch clock gene sequences were deposited in NCBI database, their accession numbers and all other related data are all listed in Additional file 1.

\section{Authors' contributions}

WYC and JSZ conceived and designed the study and wrote the paper; PW performed the experiments including RNA extraction, cDNA synthesis, and bioinformatics analysis; YLL, XZ and FZG worked for fish husbandry, sample collecting and bioinformatics analysis; JC and LC were responsible for gene rhythmic expression analysis. All authors were involved in preparing and writing the manuscript and approved the final version.

\section{Competing interests}

The authors declare that they have no competing interests.

\section{Consent for publication}

Not applicable.

\section{Ethics approval and consent to participate}

The protocol was approved by the Institutional Animal Care and Use Committee (IACUC) of Changsha University (permit \#20128945-1). All surgeries were performed under sodium pentobarbital or tricaine methanesulfonate (MS-222) anesthesia, and every effort was made to minimize the animal suffering. All fish-handling procedures during the studies were approved by the IACUC Committee.

\section{Author details}

${ }^{1}$ Department of Bioengineering and Environmental Science, Changsha University, Changsha, Hunan 410003, China. ${ }^{2}$ Collaborative Innovation Center for Efficient and Health Production of Fisheries in Hunan Province, Changde 415000, China. ${ }^{3}$ College of Life Sciences, Xinyang Normal University, Xinyang, Henan 464000, China.

Received: 8 July 2016 Accepted: 2 December 2016

Published online: 08 December 2016

\section{References}

1. Wenger CB. The regulation of body temperature. In: Rhoades RA, Tanner GA, editors. Medical Physiology. New York: Little, Brown; 1995: 587-613

2. Lazado CC, Kumaratunga HP, Nagasawa K, Babiak I, Giannetto A, Fernandes JM. Daily rhythmicity of clock gene transcripts in Atlantic cod fast skeletal muscle. PLoS One. 2014;9(6):e99172.

3. Kojima S, Shingle DL, Green CB. Post-transcriptional control of circadian rhythms. J Cell Sci. 2011;124(3):311-20.

4. Lowrey PL, Takahashi JS. Mammalian circadian biology: elucidating genome-wide levels of temporal organization. Annu Rev Genomics Hum Genet. 2004:5:407

5. Ueda HR, Hayashi S, Chen W, Sano M, Machida M, Shigeyoshi Y, lino M, Hashimoto S. System-level identification of transcriptional circuits underlying mammalian circadian clocks. Nat Genet. 2005:37(2):187-92.

6. Ptitsyn AA, Zvonic S, Conrad SA, Scott LK, Mynatt RL, Gimble JM. Circadian clocks are resounding in peripheral tissues. PLoS Comput Biol. 2006:2(3):e16.

7. Hogenesch JB, Gu YZ, Jain S, Bradfield CA. The basic-helix-loop-helix-PAS orphan MOP3 forms transcriptionally active complexes with circadian and hypoxia factors. Proc Natl Acad Sci. 1998;95(10):5474-9.

8. Froy O. Metabolism and circadian rhythms-implications for obesity. Endocr Rev. 2010:31(1):1-24

9. Braun T, Gautel M. Transcriptional mechanisms regulating skeletal muscle differentiation, growth and homeostasis. Nat Rev Mol Cell Biol. 2011;12(6):349-61

10. McCarthy JJ, Andrews JL, McDearmon EL, Campbell KS, Barber BK, Miller BH, Walker JR, Hogenesch JB, Takahashi JS, Esser KA. Identification of the circadian transcriptome in adult mouse skeletal muscle. Physiol Genomics. 2007;31(1):86-95.

11. Ahammad AS, Asaduzzaman M, Asakawa S, Watabe S, Kinoshita S. Regulation of gene expression mediating indeterminate muscle growth in teleosts. Mech Dev. 2015;137:53-65.

12. Thompson A, Vo D, Comfort C, Zakon HH. Expression evolution facilitated the convergent neofunctionalization of a sodium channel gene. Mol Biol Evol. 2014:31(8):1941-55.

13. Johnston I, Camm J-P. Muscle structure and differentiation in pelagic and demersal stages of the Antarctic teleost Notothenia neglecta. Mar Biol. 1987;94(2):183-90.

14. Van Raamsdonk W, Pool C, de Kronnie G. Differentiation of muscle fiber types in the teleost Brachydanio rerio. Anat Embryol. 1978;153(2):137-55. 
15. Barton-Davis ER, Shoturma DI, Musaro A, Rosenthal N, Sweeney HL. Viral mediated expression of insulin-like growth factor I blocks the aging-related loss of skeletal muscle function. Proc Natl Acad Sci. 1998;95(26):15603-7.

16. Bone $\mathrm{Q}$. On the function of the two types of myotomal muscle fibre in elasmobranch fish. J Mar Biol Ass UK. 1966;46(32):1-349.

17. Lin J, Wu H, Tarr PT, Zhang C-Y, Wu Z, Boss O, Michael LF, Puigserver P,

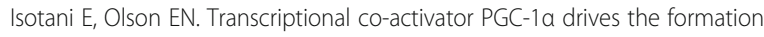
of slow-twitch muscle fibres. Nature. 2002;418(6899):797-801.

18. De Almeida-Val VMF, Gomes AC, Lopes NP. Metabolic and physiological adjustments to low oxygen and high temperature in fishes of the Amazon. Fish Physiol. 2005;21:443-500.

19. Whitmore D, Foulkes NS, Strähle U, Sassone-Corsi P. Zebrafish Clock rhythmic expression reveals independent peripheral circadian oscillators. Nat Neurosci. 1998;1(8):701-7.

20. Amaral IP, Johnston IA. Circadian expression of clock and putative clockcontrolled genes in skeletal muscle of the zebrafish. Am J Physiol Regul Integr Comp Physiol. 2012;302(1):R193-206.

21. Amaral IP, Johnston IA. Experimental selection for body size at age modifies early life-history traits and muscle gene expression in adult zebrafish. J Exp Biol. 2012;215(22):3895-904.

22. Chu WY, Liu LS, Li YL, Chen L, Wang KZ, Li HH, Du SJ, Zhang JS. Systematic identification and differential expression profiling of microRNAs from white and red muscles of Siniperca chuatsi. Curr Mol Med. 2013;13(8):1397-407.

23. Tang D, Andrews M, Cobcroft JM. The first chondracanthid (Copepoda: Cyclopoida) reported from cultured finfish, with a revised key to the species of Chondracanthus. J Parasitol. 2007;93(4):788-95.

24. Martín-Robles ÁJ, Whitmore D, Sánchez-Vázquez FJ, Pendón C, MuñozCueto JA. Cloning, tissue expression pattern and daily rhythms of Period1, Period2, and Clock transcripts in the flatfish Senegalese sole, Solea senegalensis. J Comp Physiol B. 2012;182(5):673-85.

25. Hirayama J, Sassone-Corsi P. Structural and functional features of transcription factors controlling the circadian clock. Curr Opin Genet Dev. 2005;15(5):548-56.

26. Öztürk N, Song S-H, Özgür S, Selby C, Morrison L, Partch C, Zhong D, Sancar A. Structure and function of animal cryptochromes. In: Cold Spring Harbor Symposia on Quantitative Biology: 2007. New York; Cold Spring Harbor Laboratory Press. 2007. p. 119-31.

27. Busza A, Emery-Le M, Rosbash M, Emery P. Roles of the two Drosophila CRYPTOCHROME structural domains in circadian photoreception. Science. 2004;304(5676):1503-6.

28. del Pozo A, Vera LM, Sánchez JA, Sánchez-Vázquez FJ. Molecular cloning, tissue distribution and daily expression of cry1 and cry2 clock genes in European seabass (Dicentrarchus labrax). Comp Biochem Physiol A Mol Integr Physiol. 2012;163(3):364-71.

29. Brudler R, Hitomi K, Daiyasu H, Toh H, Kucho K-i, Ishiura M, Kanehisa M, Roberts VA, Todo T, Tainer JA. Identification of a new cryptochrome class: structure, function, and evolution. Mol Cell. 2003:11(1):59-67.

30. Zhang EE, Liu AC, Hirota T, Miraglia L, Welch G, Pongsawakul PY, Liu X, Atwood A, Huss JW, Janes J. A genome-wide RNAi screen for modifiers of the circadian clock in human cells. Cell. 2009;139(1):199-210.

31. Cheng H-YM, Papp JW, Varlamova O, Dziema H, Russell B, Curfman JP, Nakazawa T, Shimizu K, Okamura H, Impey S. microRNA modulation of circadian-clock period and entrainment. Neuron. 2007;54(5):813-29.

32. Andrews JL, Zhang X, MCCarthy JJ, McDearmon EL, Hornberger TA, Russell B, Campbell KS, Arbogast S, Reid MB, Walker JR. CLOCK and BMAL1 regulate MyoD and are necessary for maintenance of skeletal muscle phenotype and function. Proc Natl Acad Sci. 2010;107(44):19090-5.

33. Lazado CC, Nagasawa K, Babiak I, Kumaratunga HP, Fernandes JM. Circadian rhythmicity and photic plasticity of myosin gene transcription in fast skeletal muscle of Atlantic cod (Gadus morhua). Mar genomics. 2014;18:21-9.

34. Patiño MAL, Rodríguez-Illamola A, Conde-Sieira M, Soengas JL, Míguez JM. Daily rhythmic expression patterns of clock1a, bmal1, and per1 genes in retina and hypothalamus of the rainbow trout, Oncorhynchus mykiss. Chronobiol Int. 2011:28(5):381-9.

35. Davie A, Sanchez JA, Vera LM, Sanchez-Vazquez J, Migaud H. Ontogeny of the circadian system during embryogenesis in rainbow trout (Oncorhynchus mykyss) and the effect of prolonged exposure to continuous illumination on daily rhythms of per1, clock, and aanat2 expression. Chronobiol Int. 2011;28(3):177-86

36. McStay E, Migaud H, Vera LM, Sánchez-Vázquez FJ, Davie A. Comparative study of pineal clock gene and AANAT2 expression in relation to melatonin synthesis in Atlantic salmon (Salmo salar) and European seabass (Dicentrarchus labrax). Comp Biochem Physiol A Mol Integr Physiol. 2014;169:77-89.

37. Velarde E, Haque R, luvone P, Azpeleta C, Alonso-Gómez A, Delgado M. Circadian clock genes of goldfish, Carassius auratus: cDNA cloning and rhythmic expression of period and cryptochrome transcripts in retina, liver, and gut. J Biol Rhythms. 2009;24(2):104-13.

38. Vatine G, Vallone D, Gothilf Y, Foulkes NS. It's time to swim! Zebrafish and the circadian clock. Febs Letters. 2011;585(10):1485-94.

39. Emery P, Reppert SM. A rhythmic Ror. Neuron. 2004:43(4):443-6.

40. Raghuram S, Stayrook KR, Huang P, Rogers PM, Nosie AK, McClure DB, Burris $L L$, Khorasanizadeh S, Burris TP, Rastinejad F. Identification of heme as the ligand for the orphan nuclear receptors REV-ERBa and REV-ERBß. Nat Struct Mol Biol. 2007;14(12):1207-13.

41. Mazzoccoli G, Tomanin R, Mazza T, D'Avanzo F, Salvalaio M, Rigon L, Zanetti A, Pazienza V, Francavilla M, Giuliani F. Circadian transcriptome analysis in human fibroblasts from Hunter syndrome and impact of iduronate-2sulfatase treatment. BMC Med Genomics. 2013;6(1):37.

42. Baggs JE, Price TS, DiTacchio L, Panda S, FitzGerald GA, Hogenesch JB. Network features of the mammalian circadian clock. PLoS Biol. 2009;7(3):563.

43. Naidu PS, Ludolph DC, To RQ, Hinterberger TJ, Konieczny SF. Myogenin and MEF2 function synergistically to activate the MRF4 promoter during myogenesis. Mol Cell Biol. 1995;15(5):2707-18.

44. Chong S-W, Nguyet L-M, Jiang Y-J, Korzh V. The chemokine Sdf-1 and its receptor Cxcr4 are required for formation of muscle in zebrafish. BMC Dev Biol. 2007;7(1):54.

45. Bustin SA, Benes V Garson JA, Hellemans J, Huggett J, Kubista M, Mueller R, Nolan T, Pfaffl MW, Shipley GL. The MIQE guidelines: minimum information for publication of quantitative real-time PCR experiments. Clin Chem. 2009;55(4):611-22.

46. Livak KJ, Schmittgen TD. Analysis of relative gene expression data using real-time quantitative $P C R$ and the $2-\Delta \Delta C T$ method. Methods. 2001;25(4):402-8.

47. Zhou RX, Meng T, Meng HB, Cheng DX, Bin SY, Cheng J, Fu GH, Chu WY, Zhang JS. Selection of reference genes in transcription analysis of gene expression of the Mandarin fish, Siniperca chuasti. Dongwuxue Yanjiu. 2010;31(2):141-6.

48. Liu J, Wang $Q$, Sun $M$, Zhu L, Yang $M$, Zhao $Y$. Selection of reference genes for quantitative real-time PCR normalization in panax ginseng at different stages of growth and in different organs. PLoS One. 2014;9(11):e112117.

49. Sun JH, Nan LH, Gao CR, Wang YY. Validation of reference genes for estimating wound age in contused rat skeletal muscle by quantitative real-time PCR. Int J Leg Med. 2012;126(1):113-20.

\section{Submit your next manuscript to BioMed Central and we will help you at every step:}

- We accept pre-submission inquiries

- Our selector tool helps you to find the most relevant journal

- We provide round the clock customer support

- Convenient online submission

- Thorough peer review

- Inclusion in PubMed and all major indexing services

- Maximum visibility for your research

Submit your manuscript at www.biomedcentral.com/submit
) Biomed Central 